\title{
Modern Fashion Design Inspired By Traditional Elements Design
}

\author{
Linshan Zhang ${ }^{1}$
}

\author{
${ }^{1}$ Jiangxi Institute of Fashion Technology, Nanchang Jiangxi, China, 330201
}

KEYWORDS: Modern Fashion Design, Traditional Elements Design, Inspire

\begin{abstract}
Our country is in the current worldwide textile and clothing production, export and consumption of the country, but on the current situation in terms of development, China's garment industry there is still a lot of issues to be resolved, whether in clothing brand innovation or to enhance on the reform we are still very large space. In this paper, the characteristics and value of traditional elements briefly described, analyzed the application and reflect the traditional elements of modern fashion design, and hope to provide for our modern costume design by reference to certain.
\end{abstract}

\section{Introduction}

With our current economy continues to develop and market innovative, competitive apparel market has become more intense up continuously reform and innovation of digital technology means and costume design concept, but also further enhance the aesthetic features of fashion design and taste [1]. People gradually began to identify the value of costume design, and thus promote their style is more and more with each passing day. In recent years, the fashion design industry began to re-play elements of traditional culture and art, and life because it has a very close relationship, from the traditional artistic style of having a simple, effective national culture can be reflected. Thus, in modern clothing design is reasonable to use the traditional elements of the design which is injected into the essence of traditional culture which can reflect its unique charm and character.

\section{The Foundation of Fashion Design Is the Traditional Cultural Elements}

The use of Chinese traditional cultural elements in modern fashion design, not only to allow the market economy to be more effective development, but also make Chinese traditional culture heritage and promoting. From a macro point of view, this is most likely to be accepted by the public and stylish form, allowing the essence of Chinese traditional culture can be passed; but only a subjective point of view, not only to enhance the cultural value of the clothing and fashion to meet the consumer demand has a very big role, but also for the expansion of the clothing brand to achieve national characteristics of domestic and foreign markets have a very important significance, it is the main method of stable development of Chinese apparel. Chinese traditional cultural elements through thousands of years of development and heritage, gradually let contemporary Chinese style rich and profound traditional culture system is formed. Not only does it effectively combines the material and spiritual culture, embodies the aesthetic psychological emotional subject, but also to today's social and cultural structures under Chinese ethnic living habits and traditional aesthetic concept is well represented [2]. It is in a simple, simple symbolic visual vocabulary, a unique visual aesthetic ideas, so that the essential characteristics of the traditional culture has been the highest artistic summary, we can say, modern fashion design art, and those with national habits 
traditional aesthetic concept of unique traditional culture, make the most of the main sources of inspiration.

\section{The Aesthetic Value of Traditional Cultural Elements in Modern Fashion Design}

Most of the use of traditional dress is flat and the proportion of crop, mostly reflecting a sense of elegant want and fluency. Chinese traditional dress also has attached more importance to form lines, which show the charm of online rhyme on. Crossed lines are the backbone of ancient Chinese clothing most basic form, after Stretch arm can be perpendicular to the line of the body. This will form the concept of clothing traditional culture hemispherical dome highlights out the day and eternal firm ground perfect expression. Clothing worn by people the moment is to make their own ideas to show up, the core language of this art is the emotional people, the people's real life philosophy portrayed, so that the spirit is reflected in the nature of the emotional world [3]. In order to get consumers, the use of means of expression contrasts, reflecting a special art form modeling, allowed more unique artistic style. In the design process should be in a calm state of mind to be absorbed into the national culture, national culture at the same time efforts will be eternal spiritual nature and emotions unfolded.

Eastern and Western art, while having a great difference in the cultural system, to produce art system are not the same, but they are in the aesthetic sense, but permeate each other and influence each other. And modern Western design very similar to the traditional oriental art elements. From above, we can see the importance of the traditional artistic elements in modern society. Want to make clothing and fashion combined with China's traditional culture has been able to achieve the goal, we must first correct treatment of Chinese traditional culture, focus on mining the meaning of traditional culture; secondly, to the aesthetic changes in market demand and consumers have proper control. Only then can we make of the contemporary mainstream European and American fashion design, so that to be truly effective with Chinese characteristics clothing creations out.

On the basis of the traditional cultural heritage, closely linked since people's lives. With the current advances in science and technology, between various regions of smooth up gradually, people began to pay attention from the national art and, thus, resulting in gradually develop the traditional artistic elements. In the absence of a unique national style and characteristics of people's attention, modern design would be very difficult to get effective development. In social life, the traditional Chinese culture, whether in ancient times or nowadays, people are advocating peace and attention to lifestyle and tradition as well as the main character, sometimes even more recognition to the local culture. Modern means of visual communication design you want to make old people's attention and sympathy would be enhanced, first, to design good location under different cultural backgrounds people's cultural psychology, so as to allow the design to be created out of being accepted [4] . Differences in the formation of a national culture Aesthetic tendency of mass psychology and mindset differences, and then into an experience handed down. For example: Chinese traditional dragon and phoenix pattern, a symbol of the Chinese nation's unique qualities, and love of traditional culture people are very fit, resulting in a very large impact on their aesthetic consciousness.

\section{The Applications and Reflection of Traditional Culture in Modern Fashion Design}

As a product of national culture costumes, only the design is defined on the basis of traditional Chinese culture, so that the clothing created out of modern charm and spirit of the Chinese nation has more charisma, to make Chinese clothing flourish, gradually out of the country, into the modern 
world fashion go. Only by allowing excellent traditional Chinese culture can be reflected in modern ethnic costumes, the traditional Chinese costumes to make real into the world, even leading the trend.

Chinese traditional cultural elements can make different forms of design can be fully met. Chinese traditional cultural elements has a special meaning and language, and each is different [5]. China plastic arts inherited the traditional Chinese art in the modern concept of fashion design. Western aesthetic taste it in the highlighted image and vivid different, its attention is vivid without attention to realism, it is the mood in the pursuit of the realm is romantic and elegant large or destruction. It not only has specific properties, but also has abstract; not only painted shape, but also ecstatic; it can be clear, but it also can not be done explicitly. Mood aesthetic effect works with a certain ambiguity and vagueness. The nearest years, the many designers in modern fashion design China gradually began to pay attention to and practice of traditional Chinese cultural elements into the play.

Description auspicious element in art and design visual communication and the environment have been widely used, these can be contemporary people pursue a better life expectations valid expression. Extending from the historical context to look up the traditional arts, one can discover the art itself is an open system, constantly under the impact of new technology and the concept of consciousness, began to improvement and innovation, has accumulated a long history of the nation formed its meaning and spirit, it is a unique culture of the Chinese nation, the nation form the heart and soul [6]. In Eastern cultures, Chinese culture is not only auspicious but is a special unique landscape, but also a very important asset, it has a very wide range of themes, rich content, a variety of forms, is irreplaceable, unique it was a unique culture in the world of art in the forest is sparkling.

\section{Conclusion}

All in all, in modern fashion design continuation and development of traditional Chinese cultural elements, allowing people to spiritual nourishment are met, based on the correct understanding of Chinese traditional culture on the extraction of its shape, extending its meaning, to convey their God, using modern, international language to describe the essence of Chinese traditional culture in the modern fashion design cleverly into the traditional cultural elements, the perfect fusion of national culture and spiritual world languages, thereby forming a trend of modern design art, thereby promoting a more cultural and social modern fashion design.

\section{Reference:}

[1] Liu Wenyan. Modern Costume Design Inspiration traditional elements of design [J]. Jilin Engineering and Technical Teachers College, 2008,05: 43-45.

[2] Zhang Zoran. application of traditional Chinese elements in modern fashion design [J]. art education research, 2011,08: 106.

[3] Li Zhengmiao. clothing design elements of traditional culture aesthetic and artistic value of the use [J]. Network wealth, 2010,04: 117-118.

[4] Qi Xiaoli. learn the ancient tradition of innovation spirit - Chinese traditional patterns in modern clothing design element in the use of design [J]. 2014,10: 154-156.

[5] Zhang Dandan. fusion of tradition and modernity: An Analysis of the use of traditional Chinese costume design element - Take the International Film Festival red carpet actress dressed as an example [J]. Art \& Design (theory), 2012,11: 111-112.

[6] Wu Guohui. Chinese traditional costumes Geometric pattern element in modern fashion design 
[J]. textile report, 2015,10: 65-67. 